\title{
ВТОРИЧНЫЙ РАК ЩИТОВИДНОЙ ЖЕЛЕЗЫ ПОСЛЕ ЛУЧЕВОЙ ТЕРАПИИ ПО ПОВОДУ МЕДУЛЛОБЛАСТОМЫ
}

\author{
Амергулов И.И., Павлова М.Г., Сыч Ю.П.
}

Федеральное государственное автономное образовательное учреждение высшего образования Первый Московский государственный медицинский университет имени И.М. Сеченова Министерства здравоохранения Российской Федерации (Сеченовский Университет)

ЦЕЛЬ: оценить частоту развития вторичного рака щитовидной железы (ЩЖ) после лучевой терапии (ЛТ) по поводу медуллобластомы (МБ).

МАТЕРИАЛЫ И МЕТОДЫ: обследовано 69 пациентов после оперативного лечения МБ с последующей ЛТ в объеме краниоспинального облучения (КСО) с бустом на заднюю черепную ямку (3ЧЯ) (+ при выявлении метастазов - буст на метастаз) в сочетании с полихимиотерапией (ПХТ) или без нее. 40 пациентов (17 юношей и 23 девушки) проходили лечение в возрасте до 16 лет; 29 (11 мужчин и 18 женщин) — в возрасте 16-48 лет. Пациентам проводилось ультразвуковое исследование (УЗИ) ЩЖ с интервалом в 12 месяцев, при выявлении узловых образований — тонкоигольная аспирационная биопсия (ТАБ)

РЕЗУЛЬТАТЫ: из 69 пациентов узлы ЩЖ выявлены у 15 (21,7\%), а рак ЩЖ - у троих (4,35\%) девушек, перенесших ЛТ в возрасте 6, 14 и 15 лет. В первом случае рак щЖ был выявлен через 13 лет после ЛТ (КСО до суммарной очаговой дозы (СОД) 35 Гр, буст на метастаз до СОД 45 Гр, буст на $34 Я$ до СОД 55 Гр); во втором - спустя 10 лет после ЛТ (КСО до СОД 40 Гр, буст на метастаз до СОД 45 Гр, буст на ЗЧЯ до СОД 55 Гр); в третьем - спустя 7 лет после ЛТ (КСО до СОД 35 Гр, буст на 34 до СОД 55 Гр). У первой девушки рак ЩЖ развился на фоне манифестного гипотиреоза, выявленного 4-мя годами ранее. Отличительной чертой данного случая явилось обнаружение в одной доле фолликулярного, а в другой - папиллярного рака. У второй девушки фокус в ЩЖ был настолько мал, что не определялся при проведении УзИ. Рак ЩЖ был заподозрен по результатам ТАБ измененного по данным УЗИ лимфоузла шеи. Во всех трех случаях узловые образования не пальпировались, а при УзИ размер 3 из 4 узлов не превышал 5 мм (папиллярные микрокарциномы). Только один узел (фолликулярная карцинома) был диаметром 12 мм. Все узловые образования имели по меньшей мере один УЗ-признак злокачественности (микрокальцинаты, нечеткие края, неровные контуры). У двух пациенток выявлены изменения лимфоузлов шеи - гипоэхогенность, неоднородность эхоструктуры, с нарушенной корково-мозговой дифференцировкой и нечеткими контурами. Ни в одном случае не было выявлено отдаленного метастазирования.

ВЫВОдЫ: после ЛТ по поводу МБ требуется настороженность в отношении рака щЖ, т.к. риск его развития существенно повышается, особенно у пациентов, лечившихся до 16 лет. Скрининговое УзИ с интервалом не менее 12 месяцев позволяет обнаружить ранние стадии агрессивного рака ЩЖ и провести своевременное лечение.

КЛЮЧЕВЫЕ СЛОВА: высокодифференцированный рак щитовидной железы; вторичные опухоли щитовидной железы; медуллобластома; лучевая терапия; ультразвуковое исследование; тонкоигольная аспирационная биопсия 